\title{
Effect of Magnetic Field on Corrosion Behavior of X52 Pipeline Steel in Simulated Soil Solution
}

\author{
Yong Yang, Yanlong Luo, Ming Sun, Junqiang Wang* \\ China Special Equipment Inspection and Research Institute, Beijing 100029 \\ "E-mail: 39530354@qq.com
}

Received: 31 May 2021 / Accepted: 19 July 2021 / Published: 10 September 2021

\begin{abstract}
Magnetic flux leakage detection is the primary method used for detecting metal damage in oil and gas pipelines. After a magnetic flux leakage test is used, a residual magnetic field remains in the steel pipeline for a long time. The influence that the residual magnetic field has on the corrosion behavior of the pipeline is not completely clear. The influence that the magnetic field has on the corrosion behavior of X52 pipeline steel in a simulated Yingtan soil solution was investigated using an open circuit potential, potentiodynamic polarization, electrochemical impedance spectroscopy, and corrosion morphology observation techniques. The results indicate that the magnetic field positively shifted the corrosion potential, increased the corrosion current density, reduced the charge transfer resistance, and basically had not impact on the corrosion morphology. When the magnetic field strength was stronger, the influence on the electrochemical corrosion behavior was greater. The influence that the magnetic field has on the electrochemical reaction process is comprehensively determined by multiple factors, such as the magnetic flux density near the electrode surface, the magnetic field gradient, the ion magnetism, and the concentration in the test electrolyte. These factors mainly promote or inhibit the corrosion process through the action of the Loren magnetic force and Kelvin force on the movement of the reactants and reaction products, such as $\mathrm{Fe}^{2+}, \mathrm{H}^{+}$, and $\mathrm{O}_{2}$ in the solution. In this study, the magnetic field promoted the development of electrochemical corrosion as a whole.
\end{abstract}

Keywords: magnetic field, magnetic flux density, simulated Yingtan soil solution, corrosion behavior

\section{$\underline{\text { FULL TEXT }}$}

(C) 2021 The Authors. Published by ESG (www.electrochemsci.org). This article is an open access article distributed under the terms and conditions of the Creative Commons Attribution license (http://creativecommons.org/licenses/by/4.0/). 